\title{
qPCR Analysis and RNAi Define Pharyngeal Gland Cell-Expressed Genes of Heterodera glycines Required for Initial Interactions with the Host
}

\author{
M. Bakhetia, P. E. Urwin, and H. J. Atkinson \\ Centre for Plant Sciences, University of Leeds, Leeds, LS2 9JT, U.K. \\ Submitted 19 December 2005. Accepted 22 September 2006.
}

\begin{abstract}
Changes in transcript abundance of genes expressed in the three pharyngeal gland cells of Heterodera glycines after host invasion were monitored by quantitative polymerase chain reaction $(\mathrm{qPCR})$ and the consequences of disrupting their expression studied by RNAi treatment prior to invasion. Two transcripts were known to be expressed in the two subventral gland cells (hg-pel and hg-eng-1), a further two in the single dorsal gland cell only (hg-gp and $h g$ syv46), and a fifth transcript (hg-cm) was expressed by both gland cell types. The qPCR study established that transcripts of $h g$-syv46 and $h g$-gp increased in abundance by 2 days postinfection (dpi), with the former remaining the most abundant. The $h \mathrm{~g}-\mathrm{cm}$ transcript level showed minor changes from 0 to 14 dpi but did fall by 21 dpi. In contrast, hg-eng-1 and hg-eng-2 messenger (m)RNA declined by 7 dpi and $h g$-pel by 14 dpi before it increased at 21 dpi. RNAi-targeting of ho-eng- 1 reduced the number of females present on the plants at 10 days. Targeting of $\mathrm{hg}-\mathrm{gp}, \mathrm{hg}-\mathrm{cm}$, and hg-pel caused a change in sexual fate favoring male development on roots. Both effects were evident after targeting hg-syv46. Suppression of hg-eng-1 mRNA levels in second-stage juveniles $\left(\mathrm{J} 2_{\mathrm{i}}\right)$ by RNAi was transient, with a recovery by 15 days of incubation in water after treatment. Presoaking $H$. glycines $\mathrm{J} 2$ with double-stranded RNA has value for studying gene function during the nematode's early interaction with a plant.
\end{abstract}

Heterodera glycines (soybean cyst nematode) and other cyst nematodes establish a compatible interaction with a host that may endure for several weeks. The second-stage juvenile $\left(\mathrm{J} 2_{\mathrm{i}}\right)$ cyst nematode invades the root from soil, preferentially close to the zone of elongation (Atkinson and Harris 1989) and traverses the cortex in a few body lengths (Robinson et al. 1987) by intracellular migration. It takes $41 \mathrm{~h}$ postinvasion (hpi) for $80 \%$ of $H$. glycines placed on the root surface of soybean plantlets to reach the endodermis and so complete the invasion process (Atkinson and Harris 1989). The establishment phase follows in which the nematode becomes a plant parasite. This involves a change in the behavior as studied for the parasitic J2 $\left(\mathrm{J} 2_{\mathrm{p}}\right)$ of $H$. schachtii. Its stylet penetrates the future feeding cell with nonvigorous thrusts and remains in this cell for approximately $7 \mathrm{~h}$. The two subventral pharyngeal glands (svpgc) empty of granules and those in the ampulla of the dorsal pharyngeal gland cell (dpgc) build up. Feeding follows the

Corresponding author: P. E. Urwin; E-mail: p.e.urwin@ leeds.ac.uk preparation period with three phases of i) secretion from the ampulla of the dpgc into the initial feeding cell, ii) pharyngeal pumping and ingestion of plant cell contents, and iii) movement of secretions along the dpgc extension to the ampulla while the stylet tip remains inserted through the plant cell wall (Wyss 1992). By $89 \mathrm{hpi}$ at $27^{\circ} \mathrm{C}, 90 \%$ of $\mathrm{H}$. glycines have molted to the third-stage juvenile (J3) stage (Atkinson and Harris 1989), indicating successful establishment. The initial feeding cell shows hypertrophy at approximately 36 hpi and a syncytium incorporating adjacent cells by partial cell wall degradation starts to form by approximately $42 \mathrm{hpi}$. The syncytium attains transfer cell status with intimate contact to xylem and phloem cells by approximately 7 days postinfection (dpi) (Endo 1964). Specific monoclonal antibodies (MAbs) reveal that some secretions of the svpgc of $\mathrm{J} 2_{\mathrm{p}}$ of $H$. glycines are used within $39 \mathrm{hpi}$, whereas a protein from the dpgc is recognized by a MAb in J3 (Atkinson and Harris 1989). A major step forward in understanding the function of gland cell secretions has been the development of complementary (c)DNA libraries for messenger (m)RNA recovered from pharyngeal glands of $H$. glycines (Gao et al. 2001, Wang et al. 2001), Meloidogyne javanica (Lambert et al. 1999), and M. incognita (Huang et al. 2003). Some predicted proteins have known functions. Both $H$. glycines and Globodera rostochiensis possess genes (eng) that encode for $\beta$-1,4-endoglucanases (Smant et al. 1998). For H. glycines, the gene product of hg-eng-2 but not hg-eng- 1 was secreted from the stylet during intracellular migration, presumably facilitating cell wall perforation by the stylet or subsequent body penetration into the plant cell (Wang et al. 1999). HG-ENG-1 differs from HG-ENG-2 in possessing a peptide linker and a cellulose-binding domain (Yan et al. 1998). An enzyme similar to HG-ENG-1 is detectable along the intracellular migration path of G. tabacum (tobacco cyst nematode) but not within its initial feeding cell (Goellner et al. 2001). A pectate lyase (PEL) has a proposed function in $G$. rostochiensis's ability to dismantle the basic framework of plant cells (Popeijus et al. 2000) and also is present in the subventral pharyngeal glands of $M$. incognita (Huang et al. 2005) and $M$. javanica (Doyle and Lambert 2002). A secreted chorismate mutase has been localized to the svpgc of $G$. pallida (Jones et al. 2003) and, additionally, to the dpgc for J2 H. glycines when within host roots (Bekal et al. 2003). The enzyme probably disrupts the shikimate pathway, modulating indole 3acetic acid (IAA) levels when released into the initial feeding cell. This may have consequences for the architecture of this cell and also may suppress plant defenses and help define virulence for $H$. glycines (Bekal et al. 2003). One protein secreted 
from the dpgc of $H$. glycines (HG-SYV46) contains a C-terminal motif similar to the CLAVATA3/ESR-related (CLE) family in Arabidopsis thaliana. Results from both mutant rescue studies and the phenotype induced by constitutive overexpression in A. thaliana suggest that there is a functional similarity of HG-SYV46 to plant-secreted CLE ligands. This nematode secretion may play a role in the development of the syncytium (Wang et al. 2005). $\mathrm{Hg}$ - $\mathrm{gp}$ was selected because, in contrast to $h g-\operatorname{syv} 46$, nothing was known of its function.

We seek to define which secretory proteins of $H$. glycines merit close study to understand the establishment of feeding cells. An experimental approach for such work is RNAi following forced ingestion of double-stranded (ds)RNA by $\mathrm{J}{ }_{\mathrm{i}}$ (Urwin et al. 2002). The consequences of RNAi have been defined for several plant-parasitic nematode genes (Bakhetia et al. 2005a; Chen et al. 2005; Fanelli et al. 2005; Lilley et al. 2005; Rosso et al. 2005; Urwin et al. 2002) and progress with the approach considered (Bakhetia et al. 2005b). We report a time course of transcript abundance by quantitative polymerase chain reaction (qPCR) and RNAi effects for five genes ( $h g$ eng-1, hg-pel, hg-cm, $h g$-syv46, and hg-gp) expressed in the pharyngeal gland cells. They were chosen because of different states of knowledge of their functional significance. We demonstrate that qPCR and RNAi together can provide a basis for prioritizing genes expressed in the gland cells for future research.

\section{RESULTS}

Relative transcript abundance of the targeted genes during early stages of nematode parasitism.

qPCR was used to quantify changes in relative transcript abundance. An initial experiment amplifying $h g$-syv 46 from a dilution series established an expected increase in threshold cycle $(\mathrm{Ct})$ by two cycles for each fourfold dilution over a range of six dilutions $\left(R^{2}=0.998\right.$, slope $=0.997$, no significant difference from 1). The experiment was extended to other genes studied and their slope was $>0.98$ in all cases. This established that the $\mathrm{Ct}$ values provide simple, reliable estimates of relative mRNA abundance. Ct values were expressed relative to $H$. $g l y$ cines actin (AF318063) (Kovaleva et al. 2004). A time course experiment was completed over 0 to 21 dpi for the five pharyngeal gland genes considered above, plus hg-eng-2. It was repeated five times using mRNA pools derived from different nematode batches on each occasion. The results are summarized in Figure 1. Only $h g-s y v 46$ and $h g$ - $g p$ expressed by the dorsal pharyngeal gland showed a significant increase between 0 to 2 dpi (one-way analysis of variance [ANOVA] with a priori contrasts, $P<0.05$ ). Both also showed a significant reduction later in the time course; however, $h g$-syv 46 remained the most abundant transcript from the pharyngeal glands for all time points. The mRNA of $h g$-eng- 1 showed a progressive fall with time of parasitism. After an initial declining trend, the transcript of $h g$-eng- 2 showed a rise at $14 \mathrm{dpi}$ and that of $h g$ pel increased at $21 \mathrm{dpi}$. $\mathrm{Hg}-\mathrm{cm}$ differed in showing only small changes in expression with time, although minor rises and falls were significant (Fig. 1).

Targeting $h g$-eng- 1 and its transcript recovery after RNAi.

Recovery of transcript abundance for $h g$-eng-l after RNAi of preinfective $\mathrm{J} 2$ is shown in Figure 2. The transcript abundance of hg-eng- 1 in $\mathrm{J} 2$ i was severely suppressed $16 \mathrm{~h}$ after forced ingestion of dsRNA targeted to induce an RNAi effect, but recovered by 5 to 10 days posttreatment (Fig. 2). RNAi treatment targeted at $h g$-eng-l did not reduce the level of $h g$ eng-2 mRNA of $\mathrm{J}_{\mathrm{i}} \mathrm{H}$. glycines that was detected by qPCR. The transcript abundance of $h g-c m$ was suppressed to $50.1 \pm$
$6.0 \%$ by 0.67 day after treatment with dsRNA targeted at that gene relative to nematodes treated with a dsRNA targeted at green fluorescent protein (GFP). Similar experiments aimed at $h g$-syv46, hg-pel, and hg-gp did not detect a decrease in transcript abundance. Expression levels of $h g$-syv46 and hg-pel were low before root invasion. We consider that this makes it difficult to detect reliably any further reduction following an RNAi effect.

\section{Establishment of $\mathrm{H}$. glycines 10 days after dsRNA treatment targeted at genes expressed in pharyngeal gland cells.}

The number of established nematodes within the roots of 7 to 15 soybean plants per treatment was assessed at $10 \mathrm{dpi}$, before males begin to emerge from roots. The number was expressed relative to that for nematodes that were $g f p$ dsRNA treated as $\mathrm{J} 2_{\mathrm{i}}$ on all experimental occasions (data not shown). This normalization allowed direct comparison between experiments for which different percentage establishments sometimes occur.

One-way ANOVA with a priori contrasts established that the $g f p$ dsRNA-treated $\mathrm{J} 2$ and those $\mathrm{J} 2$ exposed to octopamine only established on plants at equal densities. This demonstrates that uptake of the $g f p$ dsRNA did not perturb establishment. Fewer nematodes established on the plants after treatment with dsRNA targeted at either $h g$-syv 46 or $h g$-eng- 1 than for the two controls $(P<0.05$ and 0.001 , respectively; oneway ANOVA and a priori contrasts) (Fig. 3). This reduced ability to establish did not occur after treatment with dsRNA targeted at $h g-g p, h g-c m$, or $h g-p e l$.

\section{Sexual fate of established $\boldsymbol{H}$. glycines 10 days after dsRNA treatment targeted at genes expressed in pharyngeal gland cells.}

The proportion of females to males established on the plants after 10 days differed according to the gene targeted by dsRNA treatment of $\mathrm{J} 2{ }_{\mathrm{i}} H$. glycines. With the method of infection used throughout the experiments, the frequency of nematodes that could not be sexed was extremely low $(<2 \%)$. These occasional individuals were not considered further. The proportion of females after $g f p$ dsRNA treatment was $0.77 \pm 0.048$, which is typical of the values obtained for $H$. glycines infecting plants under favorable conditions (Atkinson and Harris 1989). The proportion of females following RNAi of the targeted genes was as follows: $h g$-syv46, $0.42 \pm 0.08 ; h p$ - $g p, 0.27 \pm 0.11$; $h$-eng- 1 , $0.57 \pm 0.04$; hg-pel, $0.28 \pm 0.08$; and hg-cm, $0.28 \pm 0.11$ (Fig. 4). For the control gene, there were $9.9 \pm 0.69$ females/plantlet after dsRNA treatment targeted at $g f p$.

The proportion of females was similar for the two control treatments but significantly less after dsRNA for treatment targeting each of four of the pharyngeal gland cell genes $(P<$ 0.001 ; one-way ANOVA and a priori contrasts). Two of these genes are expressed in the dpgc ( $h g-s y v 46$ and $h g-g p)$. The third, $h g$-pel, is expressed in the svpgc only and the fourth, $h g$ $\mathrm{cm}$, is expressed in both types of pharyngeal gland cells in $H$. glycines (Doyle and Lambert 2003). Pretreatment with hg-eng1 dsRNA did not result in a significant shift in sexual fate of the parasites. This result and the control involving dsRNA $g f p$ establish that the effects on sexual fate for other genes are not caused by a general stress associated with the forced ingestion of dsRNA.

\section{DISCUSSION}

An RNAi effect was evident for dsRNA specifically targeted at five different genes that are expressed in the three pharyngeal gland cells. The results are unlikely to be due to effects on 
nonhomologous sequences. They did not occur after targeting either a gene from another genome $(g f p)$ or a vitellogenin that is first expressed only after establishment has occurred. The sequence identity of hg-eng-l with the other hg-eng genes over the region used to target by RNAi was only between 44 and 59\%. Hg-eng-1 has regions over approximately $100 \mathrm{bp}$ with an identity of $>95 \%$ with $h g$-eng- $2, h g$-eng- 3 , and $h g$ eng-4. Cosuppression of $h g$-eng-2 did not occur for a dsRNA targeted at $h g$-eng-1. The RNAi effect seems to be on target for hg-eng-1. Transcript abundance was suppressed after RNAi targeting either $h g-e n g-l$ (Fig. 2) or $h g-c m$. In Caenorhabditis elegans, an RNAi effect has been detected over more than one generation. More work is required to determine whether such long-range effects do occur even for a single generation of $>20$ days for cyst nematodes, given that the $h g$-eng- $l$ transcript level recovered between 5 and 10 days for $\mathrm{J} 2$. The high message level at $10 \mathrm{dpi}$, before its reduction by 15 dpi to approximately that for nematodes not subject to RNAi treatment, is consistent with a recovery process. It indicates a possible homeostatic feedback after secretion that normally restores $\beta-1,4$ endoglucanase levels in the subventral pharyngeal glands as invasion progresses and the protein is secreted. The transcripts
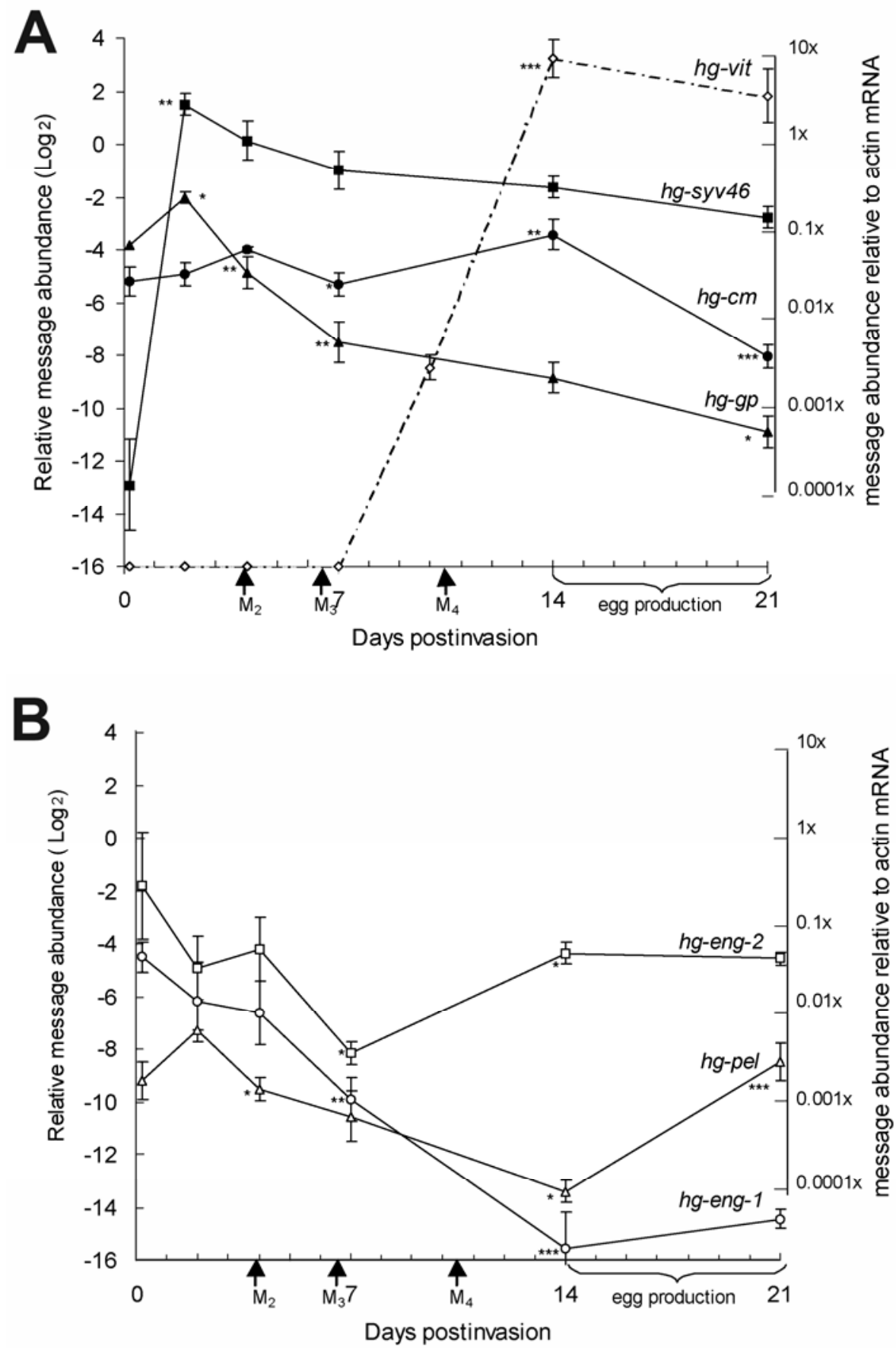

Fig. 1. Quantitative measurement of messenger (m)RNA abundance of A, three genes known to express in the dorsal pharyngeal gland cell plus a vitellogenin (hg-vit) and $\mathbf{B}$, a further three expressed in the two subventral pharyngeal gland cells of Heterodera glycines. The timing of the first individuals passing through each of three molts in planta is shown. The period of egg production by females continues beyond the period of study. Values are means \pm standard error of the mean, with statistical significance established relative to the mean immediately preceding it in the time course for that gene by one-way analysis of variance with a priori contrasts $(*, * *$, and $* * *=P<0.05,0.01$, and 0.001 , respectively). The vitellogenin was included as an indicator of female maturity because it is not expressed in $\mathrm{J} 2_{\mathrm{i}}$. 
for $h g$-svy46 and $h g$-pel are sufficiently rare before root invasion that any RNAi-induced suppression could not be detected reliably by qPCR. The difference in low abundance of $h g$-pel reported in this work relative to indications from in situ localization (de Boer et al. 2002) may arise because, in contrast to the in situ data, the PCR technique is quantitative. A change in the sex ratio was detected for $h g-g p$ although suppression of its transcript was not detected at $16 \mathrm{~h}$ posttreatment with dsRNA. There is too little data yet to determine which of the factors discussed by Bakhetia and associates (2005a) was responsible for this. Actin has been used before as a positive control when studying developmental expression of a pectate lyase gene in M. incognita (Huang et al. 2005). Our results show that there is a slight decline in actin transcript abundance from 0 to $7 \mathrm{dpi}$ but no further fall by $21 \mathrm{dpi}$ (data not shown).

Forced dsRNA ingestion induces RNAi effects for genes of

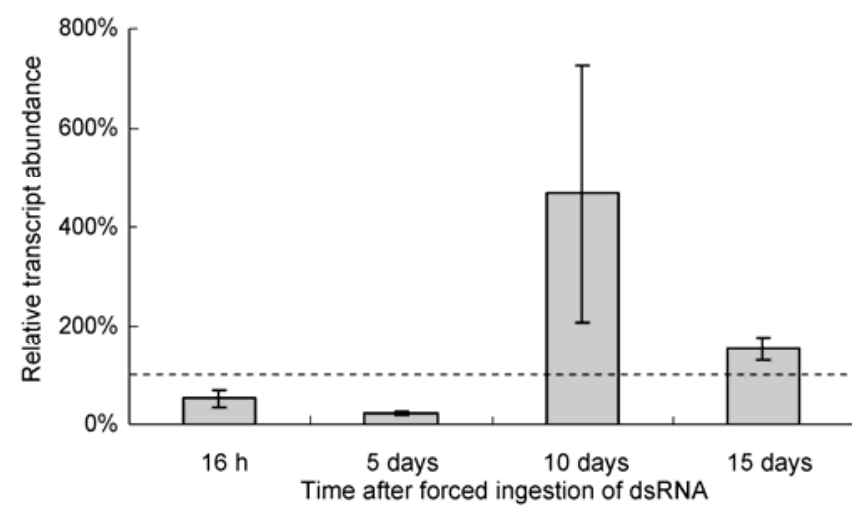

Fig. 2. A real-time polymerase chain reaction time course study of the recovery of hg-eng-l expression after pretreatment of second-stage juvenile (J2) Heterodera glycines with hg-eng-1 double-stranded (ds)RNA. Following $16 \mathrm{~h}$ of exposure to dsRNA, the $\mathrm{J} 2$ nematodes were maintained in water and sampled at $16 \mathrm{~h}$ and 5,10 , and 15 days post treatment. The mean at 15 days differs significantly from that $16 \mathrm{~h}$ after dsRNA treatment $(P<$ $0.05)$. Values are relative to the mean transcript abundance for $\mathrm{J} 2_{\mathrm{i}}$ at the start of the experiment that were not exposed to dsRNA.

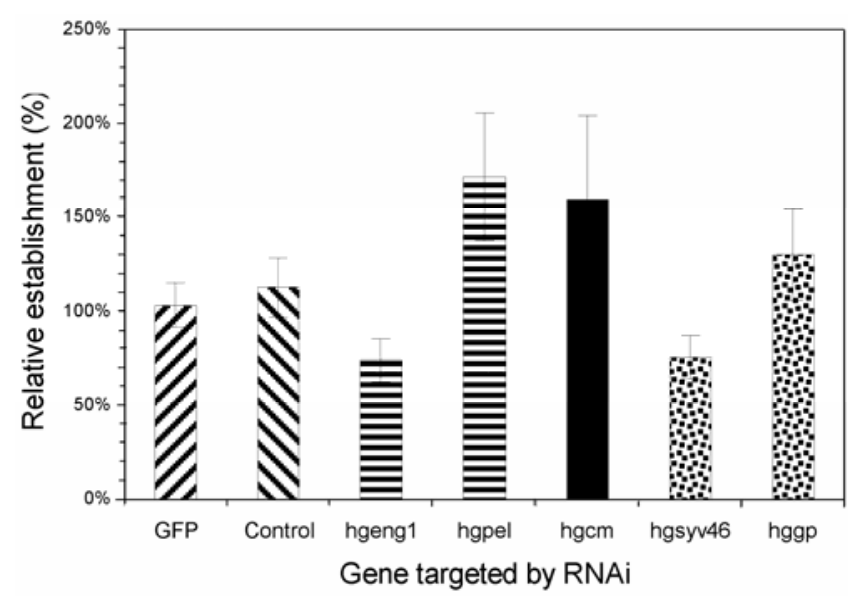

Fig. 3. Effect on the establishment of Heterodera glycines in roots of soybean after presentation of double-stranded (ds)RNA-treated second-stage juveniles (J2) to the roots of plants. Means are expressed \pm standard error of the mean values relative to establishment for J2 after dsRNA green fluorescent protein ( $g f p$ ) pretreatment (GFP). The second control is for J2 exposed to octopamine only (Control). Bars with horizontal lines indicate expression in subventral glands, the solid bar indicates expression in both subventral and dorsal glands, and stippled bars indicate expression in the dorsal gland. The establishment of control J2 treated with $g f p$-dsRNA is taken as $100 \%$. cyst nematodes that are expressed in the intestine (cysteine proteinase $h g$-cpl-1 and $g p-c p-1$ ) (Urwin et al. 2002), the female reproductive system (aminopeptidase hg-amp-1) (Lilley et al. 2005), the svpgc (Chen et al. 2005, this work), the dpgc cell (this work), and a gene probably functional in the extracellular matrix (C-type lectin) (Urwin et al. 2002). The extracellular matrix also can be targeted for $M$. incognita (Bakhetia et al. 2005a), as can a chitin synthase gene of $M$. artiellia after soaking egg masses in an appropriate dsRNA (Fanelli et al. 2005). An RNAi effect occurs in a wide range of cells in cyst and, presumably, root-knot nematodes. This suggests systemic dispersal of the RNAi effect after oral uptake of dsRNA occurs as for C. elegans (Winston et al. 2002). Forced uptake of dsRNA by preinvasion $\mathrm{J} 2 \mathrm{~s}$ allows RNAi-mediated study of gene function in a wide range of the tissues and cell types of later parasitic stages. In C. elegans, an RNAi effect has been detected over more than one generation. More work is required to determine whether such long-range effects do occur even for a single generation of $>20$ days for a cyst nematode, given that the $h g$ eng-1 transcript level recovered within 15 days for $\mathrm{J} 2$.

Hg-eng- 2 was not subject to RNAi in this work because targeting a similar gene in $G$. rostochiensis reduces root invasion (Chen et al. 2005). Previous immunolocalization studies suggested that hg-eng- 1 differs from hg-eng- 2 in two ways. Its gene product is not secreted during root invasion (Wang et al. 1999) and it is abundantly expressed before root invasion (Gao et al. 2004). Our results demonstrate that its transcript is abundant in $\mathrm{J} 2{ }_{\mathrm{i}}$ but also showed that it fell progressively in parasitic stages (Fig. 1). The lack of effect on sexual fate of $H$. glycines following RNAi of hg-eng- 1 suggests that it had no important role in establishment. Its likely role is early in the infection process, during either invasion or, possibly, preparation to feed.

RNAi of $h g$-gp, $h g$-cm, and $h g$-pel altered sexual fate in favor of males but did not suppress the number of parasites. Their loss of function may have a consequence only after establishment is achieved. Sexual fate is morphologically defined for $H$. schachtii before the molt to J3 $\left(\mathbf{M}_{2}\right)$ (Wyss 1992). Environmental effects on sexual fate associated with feeding site quality are evident from position on the root system

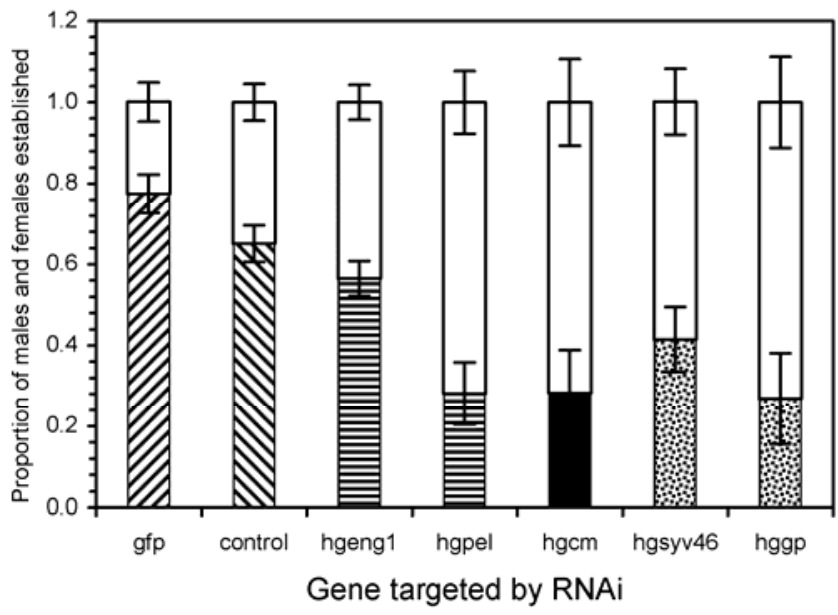

Fig. 4. Proportion of Heterodera glycines developing as males or females 10 days after presentation of double-stranded (ds)RNA-treated secondstage juveniles $(\mathrm{J} 2)$ to the roots of plants. Means are expressed \pm standard error of the mean values relative to establishment for J2 after dsRNAgreen fluorescent protein ( $g f p)$ pretreatment. The second control is for $\mathrm{J} 2$ exposed to octopamine only (Control). Bars with horizontal lines indicate expression in subventral glands, the solid bar indicates expression in both subventral and dorsal glands, and stippled bars indicate expression in the dorsal gland. The proportion of males and females is shown by the proportion of the bar that is open (males) versus filled (females). 
(Sobczak et al. 1997) or after uptake of proteinase inhibitors (Urwin et al. 1998). Possibly, RNAi of hg-pel and hg-cm favors male development by compromising the role in syncytial development of their protein products normally released from the svpgc into the selected plant cell before the first feed (Wyss 1992). This is consistent with a proposed role for the HG-PEL enzyme continuing after that in invasion and migration. Its suggested ability to dismantle the basic framework of plant cells (Popeijus et al. 2000) may have a value even after migration ends during initial establishment of the feeding cell. It also might help maintain subsequent feeding cell plasticity, as was suggested for pectate lyase activity of $M$. javanica (Doyle and Lambert 2002) and M. incognita (Huang et al. 2005). Its transcript abundance rose between 14 and 21 dpi, possibly when the root lesions develop that accommodate the enlarged saccate female. The abundant expression in this period might be within developing eggs; however, no other gene studied showed a similar increase so soon after egg production commenced.

Chorismate mutase is expressed in all three pharyngeal gland cells of J2 H. glycines (Bekal et al. 2003; Gao et al. 2003) but just the svpgc of $G$. pallida before invasion (Jones et al. 2003). The transcript level declines at 2 and $5 \mathrm{dpi}$, with some recovery of expression level in young females (Jones et al. 2003). RNAi suggests that its normal expression is not essential for invasion by $H$. glycines. The enzyme probably disrupts the shikimate pathway, modulating IAA levels and altering the developmental fate of feeding cells. It also may suppress plant defenses and be involved in defining virulence during the early phases of parasitism of $H$. glycines (Bekal et al. 2003). Such roles are consistent with an RNAi effect that compromises the quality of the feeding site in preparation for feeding and during initial feeds before sexual fate is determined.

$H g$-syv46 differs from the other genes studied in affecting both establishment and sexual fate. As a product of the dpgc, $H G-S Y V 46$ is unlikely to be secreted until the first feed. The dual consequences of RNAi suggest that loss of its gene product induces failure of the feeding site for some individuals and acts in time to affect the sexual fate of other individuals. Its high expression after invasion may reflect that it does not encode an enzyme, in contrast to hg-eng-1, hg-eng-2, hg-pel, and hg-cm. Its protein product has similarity to the CLE family of $A$. thaliana. The best-studied plant protein of this group (CLV3) encodes a peptide ligand that is involved in controlling the balance between meristem cell proliferation and differentiation. $\mathrm{Hg}$-syv46 may produce a ligand that disrupts the normal pattern of plant cell differentiation at the feeding site. It may help maintain the integrity of the syncytium (Wang et al. 2005).
Our work establishes that RNAi helps to identify genes of particular interest for further study from the very many now known to be secreted by the three pharyngeal gland cells. The different transcripts show considerable gene-specific changes in temporal expression during invasion, establishment, and subsequent feeding of $H$. glycines. Only those nematode genes that function after uptake of the first feed are potential targets for novel resistance via delivery of dsRNA from the plant (Bakhetia et al. 2005b). This suggests that hg-eng-l is not of interest for such an approach, in contrast to $h g$-syv46. It becomes and remains an abundant transcript only after establishment, and RNAi targeting of this gene disrupts both normal rates of parasite establishment and sexual fate.

\section{MATERIALS AND METHODS}

\section{RNA isolation and real-time PCR.}

RNA was extracted from 3,000 preparasitic J2 nematodes. Approximately 150 to 200 nematodes were collected for the postparasitic stages at 2, 4, 7, 10, 14, and 21 dpi. At 10, 14, and 21 dpi only, nematodes were dissected from the root material before RNA preparation. For all postinfection time points, the nematodes were from two series of plants that were set up on different occasions. Material was collected from infection points for each of five plants in both experiments. A minimum of five pools of RNA were prepared for each time point using different samples of nematodes. The total RNA was extracted according to the manufacturer's instructions using the RNeasy Plant minikit (catalog number 74904; Qiagen, Hilden, Germany) and DNase treated on the column using the Qiagen RNase-free DNase set (catalog number 79254). RNA (200 ng) was reverse transcribed in $20 \mu \mathrm{l}$ using Superscript II reverse transcriptase (catalog number 18064-014; Invitrogen, Paisley, U.K.) according to the manufacturer's instructions, with the exception that a cocktail of random hexamers and anchored oligo $_{15}$ primers was used to prime cDNA synthesis at a final concentration of $7.5 \mu \mathrm{M}$.

Real-time PCR was used to assess the level of gene expression in the time course study (at time points described above) and to analyze transcript suppression in the $\mathrm{J} 2_{\mathrm{i}}$ nematodes after the RNAi treatments. From cDNA synthesis reactions, $5 \mu \mathrm{l}$ was removed, diluted to $200 \mu \mathrm{l}$ with sterile distilled water, and used to make threefold serial dilutions from $1 \times$ to $81 \times$. Water $(585 \mu \mathrm{l})$ was added to the remaining $15 \mu \mathrm{l}$ of cDNA, and $5 \mu \mathrm{l}$ of each sample was used per PCR reaction. Primers used for qPCR reactions are detailed in Table 1 . Reactions were performed in triplicate on a BioRad ICycler (BioRad, Hercules, CA, U.S.A.) real-time PCR machine using BioRad IQ SYBR

Table 1. Details of primers used for quantitative polymerase chain reaction (qPCR) and to generate double-stranded (ds)RNA ${ }^{\mathrm{a}}$

\begin{tabular}{|c|c|c|c|}
\hline Gene & dsRNA product (bp) & Primers for RNAi experiment & Primers for PCR \\
\hline \multirow[t]{2}{*}{ hg-eng-1 } & 1,426 & F GTGCCGACTCCAAGCAACTCATC & F AAAGACAAAGCGCAAAATGG \\
\hline & & R ACATTTCTTCGTCGTCAC & R TACTTTGGTCAACATTTTATG \\
\hline \multirow[t]{2}{*}{ hg-pel } & 776 & F TCATTCTATTGGTCATAACTTTTGT & F ACTTTGCATGGCCAAAAATC \\
\hline & & R CGCAATTTTAACTGCCGAGGC & R GGCTCATAATTCGCTTGAGG \\
\hline \multirow[t]{2}{*}{$h g-\mathrm{cm}$} & 798 & F GAATTCGTCCGTCGTTTCATTTTC & F GGAACCGCAACACTTTCAT \\
\hline & & R GCCGTTTCGTCAATTTGTGCC & R GCTTTTCCCGTTCAAAATCA \\
\hline \multirow[t]{2}{*}{$h g-s y v 46$} & 414 & F GCCAAACATTTTCAAAATCC & F CGTCTCTCGGCTTCTACTGG \\
\hline & & R TGATGATGTGGGTCGGG & R CCAGCGGTGACAATTCTTTT \\
\hline \multirow[t]{3}{*}{$h g-g p$} & 678 & F GCGCACTTTTCTGTTCATAGCTGT & F AACAACAAATCGCCAACGA \\
\hline & & R CGACTGTCAGCGCAGTAGGGCTG & R ACGTTCTGCACCACATTTGA \\
\hline & & R CAGTCCGCTGACGTAC & R TCTTCCTGCGTCATGTTCTG \\
\hline \multirow[t]{2}{*}{ hg-vit } & $\ldots$ & $\ldots$ & F CGGCCTACTTCTGGAACACCA \\
\hline & & $\ldots$ & R CGCACTTTGTACGGCACTT \\
\hline \multirow[t]{2}{*}{ hg-eng-2 } & $\ldots$ & $\ldots$ & F TGGAGCCTGTTGGACCAAC \\
\hline & & $\ldots$ & R TACCATATTGCCAGACTGC \\
\hline
\end{tabular}

\footnotetext{
${ }^{\text {a }}$ Sizes of dsRNA products are shown. $\mathrm{F}=$ forward and $\mathrm{R}=$ reverse.
} 
Green reaction mix with the following reaction conditions: $95^{\circ} \mathrm{C}$ for $15 \mathrm{~s}$ and $60^{\circ} \mathrm{C}$ for $30 \mathrm{~s}$ (40 cycles). Initial data analysis was carried out using the BioRad ICycler software, which created $\mathrm{Ct}$ values and extrapolated relative levels of PCR products from standard curves. Melt curves were done routinely, and this allowed the possibility of both contamination and primer dimers to be discounted. Actin was used as a positive control in all experiments.

\section{Preparation of dsRNA of $\boldsymbol{H}$. glycines genes.}

Sequences for $\beta$-1,4-endoglucanase (hg-eng-1, accession AF006052), pectate lyase ( $h$ g-pel, accession AF520566), chorismate mutase ( $\mathrm{hg}-\mathrm{cm}$, accession AF520565), gland protein (hg-gp, accession AF502392), and hg-syv46 (accession AF273728) were identified from the GenBank database. Using HindIII and XbaI, 1,426- and 776-bp fragments of hg-eng-1 and $h g$-pel, respectively, were cloned. XhoI and XbaI were used to clone a 798-bp fragment of $h g$-cm-1, and $h g$-syv 46 and $h g$ - $g p$ were cloned as 414- and 678-bp fragments, respectively. A fragment of the vitellogenin gene, $h g$-vit, was cloned as a 463-bp SacI and PstI fragment. All amplified fragments were cloned into the vector pPD129.36 (The Fire Lab, Stanford, CA, U.S.A.), in which the multiple cloning site is flanked by T7 promoters. Sense and antisense RNA was transcribed using an Ampliscribe T7 high-yield transcription kit (Cambio, Cambs, U.K.) according to the manufacturer's instructions. Sense and antisense transcripts then were annealed for $30 \mathrm{~min}$ at $37^{\circ} \mathrm{C}$ and analyzed by agarose gel electrophoresis. The primers used for amplification of target gene sequences to be cloned into pPD129.36 are shown in Table 1.

\section{RNAi treatment of $\mathrm{H}$. glycines.}

The RNAi soaking method of Urwin and associates (2002) was used, except the incubation time was increased from 4 to 16 h. Cysts of $H$. glycines were extracted from infected soil by a standard flotation and sieving method. Cysts were sterilized as described by Urwin and associates (1995). The cysts were rinsed and placed in a hatching jar at $25^{\circ} \mathrm{C}$. The hatched juveniles of $H$. glycines were collected in $1.5-\mathrm{ml}$ microfuge tubes. Approximately 5,000 J2s were incubated in soaking buffer (50 $\mathrm{mM}$ octopamine in M9 salts) (Sigma, Poole, Dorset, U.K.) containing the appropriate dsRNA $(2 \mu \mathrm{g} / \mu \mathrm{l})$ in a $1.5-\mathrm{ml}$ microfuge tube for $16 \mathrm{~h}$ at room temperature with occasional agitation. All RNAi experiments were carried out twice on different occasions using separate batches of hatched nematodes. Controls were incubated in either soaking buffer alone or with $g f p$ dsRNA (nonspecific dsRNA). A proportion of the dsRNAtreated and control animals (no dsRNA or $g f p$ dsRNA) were used for quantitative PCR analysis and the rest of the animals were used to infect plants as described below.

For the experiment to determine transcript recovery of $h g$ eng-1, the nematodes were washed copiously with water following incubation in dsRNA. Approximately 1,000 nematodes then were removed for qPCR analysis. The remaining nematodes were maintained in water at $27^{\circ} \mathrm{C}$ and the water was changed daily. Further 1,000-nematode samples were removed at 5,10 , and 15 days. The experiment was carried out in duplicate using separate batches of hatched nematodes.

\section{Infection of plants in pouches.}

Glycine max (soybean) plants were grown in CYG seed growth pouches (Mega International, Minneapolis, MN, U.S.A.) and infected with $\mathrm{J} 2$ nematodes as described (Atkinson and Harris 1989). Three points per plant (10 plants in total for each treatment) were infected with 15 nematodes on each experimental occasion. Plants were infected with nematodes treated with soaking buffer only, soaking buffer containing dsRNA of the gene of interest (RNAi), or $g f p$ dsRNA. The pouches were placed $15 \mathrm{~mm}$ apart in a box, immersed in $2 \mathrm{~cm}$ of water, and grown in a temperature-controlled incubator at $27^{\circ} \mathrm{C}$ and 50 to $60 \%$ humidity for 10 days. All experiments were performed in duplicate.

Nematodes within the roots were stained using acid fuchsin as described previously (Urwin et al. 2002) and dissected from the roots using $0.6-\mathrm{mm}$ needles with the aid of a stereo binocular microscope.

\section{LITERATURE CITED}

Atkinson, H. J., and Harris, P. D. 1989. Changes in nematode antigens recognized by monoclonal antibodies during early infections of soya beans with the cyst nematode Heterodera glycines. Parasitology 98:479-487.

Bakhetia, M., Atkinson, H. J., and McPherson, M. J. 2005a. RNA Interference of Dual Oxidase in the plant nematode Meloidogyne incognita. Mol. Plant-Microbe Interact. 18:1099-1106.

Bakhetia, M., Charlton, W. L., Urwin, P. E., McPherson, M. J., and Atkinson, H. J. 2005b. RNA interference and plant-parasitic nematodes. Trends Plant Sci. 10:362-367.

Bekal, S., Niblack, T. L., and Lambert, K. N. 2003. A chorismate mutase from the soybean cyst nematode Heterodera glycines shows polymorphisms that correlate with virulence. Mol. Plant-Microbe Interact. 16:439-446.

Chen Q., Rehman, S., Smant, G., and Jones, J. T. 2005. Functional analysis of pathogenicity proteins of the potato cyst nematode Globodera rostochiensis using RNAi. Mol. Plant-Microbe Interact. 18:621-625.

de Boer, J. M., McDermott, J. P., Davis E. L., Hussey, R. S., Popeijus, H., Smant, G., and Baum, T. J. 2002. Cloning of a putative pectate lyase gene expressed in the subventral esophageal glands of Heterodera glycines. J. Nematol. 34:9-11.

Doyle, E. A., and Lambert, K. N. 2002. Cloning and characterization of an esophageal-gland-specific pectate lyase from the root-knot nematode Meloidogyne javanica. Mol. Plant-Microbe Interact. 15:549-556.

Doyle, E. A., and Lambert, K. N. 2003. Meloidogyne javanica chorismate mutase 1 alters plant cell development. Mol. Plant-Microbe Interact. 16:123-131.

Endo, B. Y. 1964. Penetration and development of Heterodera glycines in soybean roots and related anatomical changes. Phytopathology 54:79-88.

Fanelli, E., Di Vito, M., Jones, J. T., and DeGiorgi, C. 2005. Analysis of chitin synthase function in a plant parasitic nematode, Meloidogyne artiellia, using RNAi. Gene 349:87-95.

Gao, B., Allen, R., Maier, T., Davis, E. L., Baum, T. J., and Hussey, R. S. 2001. Identification of putative parasitism genes expressed in the oesophageal gland cells of the soybean cyst nematode Heterodera glycines. Mol. Plant-Microbe Interact. 14:1247-1254.

Gao, B., Allen, R., Maier, T., Davis, E. L., Baum, T. J., and Hussey, R. S. 2003. The parasitome of the phytonematode Heterodera glycines. Mol. Plant-Microbe Interact. 16:720-726.

Gao, B., Allen, R., Davis, E. L., Baum, T. J., and Hussey, R. S. 2004. Developmental expression and biochemical properties of a $\beta$-1,4-endoglucanase family in the soybean cyst nematode, Heterodera glycines. Mol. Plant Pathol. 5:93-104.

Goellner, M., Wang, X., and Davis, E. L. 2001. Endo- $\beta$-1-4-glucanase expression in compatible plant-nematode interactions. Plant Cell 13:22412255 .

Huang, G., Gao, B., Maier, T., Allen, R., Davis, E. L., Baum, T. J., and Hussey. R. S. 2003. A profile of putative parasitism genes expressed in the esophageal gland cells of the root-knot nematode Meloidogyne incognita. Mol. Plant-Microbe Interact. 16:376-381.

Huang, G., Dong, R., Allen, R., Davis, E. L., Baum, T. J., and Hussey, R. S. 2005. Developmental expression and molecular analysis of two Meloidogyne incognita pectate lyase genes. Int. J. Parasitol. 35:685692.

Jones, J. T., Furlanetto, C., Bakker, E., Banks, B., Blok, V., Chen, Q., Phillips, M., and Prior, A. 2003. Characterization of a chorismate mutase from the potato cyst nematode Globodera pallida. Mol. Plant Pathol. 4:43-50.

Kovaleva, E. S., Masler, E. P., Skantar, A. M., and Chitwood. D. J. 2004. A novel matrix metalloprotease from the cyst nematodes Heterodera glycines and Globodera rostochiensis. Mol. Biochem. Parasitol. 136:109112.

Lambert, K. N., Allen, J. K. D., and Sussex, I. M. 1999. Cloning and characterization of an oesophageal-gland specific chorismate mutase from the phytoparasitic nematode Meloidogyne javanica. Mol. Plant-Microbe Interact. 12:328-336. 
Lilley, C. J., Goodchild, S. A., Atkinson, H. J., and Urwin, P. E. 2005. Cloning and characterisation of a Heterodera glycines aminopeptidase cDNA. Int. J. Parasitol. 35:1577-85.

Popeijus, H., Overmars, H., Jones., J. T., Blok, V. C., Goverse, A., Helder, J., Schots, A., Bakker, J., and Smant, G. 2000. Degradation of plant cell walls by a nematode. Nature 406:36-37.

Robinson, M. P., Atkinson, H. J., and Perry, R. N. 1987. The influence of soil moisture and storage time on persistence and infectivity of second stage juveniles of the potato cyst nematodes Globodera rostochiensis and G. pallida. Rev. Nematol. 10:343-348.

Rosso, M. N., Dubrana, M. P., Cimbolini, N., Jaubert, S., and Abad, P. 2005. Application of RNA interference to root-knot nematode genes encoding oesophageal gland proteins. Mol. Plant-Microbe Interact. 18:615-620.

Smant, G., Stokkermans, J., Yan, Y., de Boer, J. M., Baum, T., Wang, X., Hussey, R. S., Davis, E. L., Gommers, F. J., Henrissat, B., Helder, J., Schots, A., and Bakker, J. 1998. Endogenous cellulases in animals: cloning of expressed $\beta$-1,4-endoglucanase genes from two species of plantparasitic cyst nematodes. Proc. Natl. Acad. Sci. U.S.A. 95:4906-4911.

Sobczak, M., Golinowski, W., and Grundler, F. M. W. 1997. Changes in the structure of Arabidopsis thaliana roots induced during development of males of the plant parasitic nematode Heterodera schachtii. Eur. J. Plant Pathol. 103:113-124.

Urwin, P. E., Atkinson, H. J., Waller, D. A., and McPherson, M. J. 1995. Engineered oryzacystatin-I expressed in transgenic hairy roots confers resistance to Globodera pallida. Plant J. 8:121-131.

Urwin, P. E., McPherson, M. J., and Atkinson, H. J. 1998. Enhanced trans- genic plant resistance to nematodes by dual proteinase inhibitor constructs. Planta 204:472-479.

Urwin, P. E., Lilley, C. J., and Atkinson, H. J. 2002. Ingestion of doublestranded RNA by preparasitic juvenile cyst nematodes leads to RNA interference. Mol. Plant-Microbe Interact. 15:747-752.

Wang, X., Meyers, D., Yan, Y., Baum, T., Smant, G., Hussey, R., and Davis E. 1999. In planta localization of $\beta$-1-4-endoglucanase secreted by Heterodera glycines. Mol. Plant-Microbe Interact. 12:64-67.

Wang, X., Allen, R., Ding, X., Goellner, M., Maier, T., de Boer, J. M., Baum., T. J., Hussey, R. S., and Davis, E. L. 2001. Signal peptide-selection of cDNA cloned directly from the esophageal gland cells of the soybean cyst nematode Heterodera glycines. Mol. Plant-Microbe Interact. 14:536-544.

Wang, X., Mitchum, M. G., Gao, B., Li, C., Diab, H., Baum, T. J., Hussey, R. S., and Davis, E. L. 2005. A parasitism gene from a plant-parasitic nematode with function similar to CLAVATA3/ESR (CLE) of Arabidopsis thaliana. Mol. Plant Pathol. 6:187-191.

Winston, W. M., Molodowitch, C., and Hunter, C. P. 2002. Systemic RNAi in $C$. elegans requires the putative transmembrane protein SID-1. Science 295:2456-2459.

Wyss, U. 1992. Observations of the feeding behaviour of Heterodera schachtii throughout development, including events during moulting. Fundam. Appl. Nematol. 15:75-89.

Yan, Y., Smant, G., Stokkermans, J., Qin, L., Helder, J., Baum, T. J., Schots, A., and Davis, E. L. 1998. Genomic organization of four beta1,4-endoglucanase genes in plant-parasitic cyst nematodes and its evolutionary implications. Gene 220:61-70. 